Vida asociativa al ras del suelo en una aldea Peronista activismo obrero y popular en Mar del Plata, 1943-1955

Agustín Nieto

páginas / año 7 - n 14 / ISSN 1851-992X / pp. 41-61 / 2015

http://revistapaginas.unr.edu.ar/index.php/RevPaginas

\title{
Vida asociativa al ras del suelo en una aldea peronista activismo obrero y popular en Mar del Plata, 1943-1955*
}

\author{
At ground level associative life in a Peronist village. Labour and popular \\ activism in Mar del Plata, 1943-1955
}

\author{
Agustín Nieto \\ Grupo de Estudios Sociales y Marítimos (Universidad Nacional de Mar del Plata) - \\ Consejo Nacional de Investigaciones Científicas y Técnicas, Argentina \\ agustin.nieto77@gmail.com
}

\begin{abstract}
Resumen
En este artículo ensayamos un mapeo de la activación política a ras del suelo. Rastreamos las distintas formas de asociacionismo obrero y popular en la Mar del Plata de mediados del siglo XX: sindicatos, bibliotecas, sociedades de fomento. También nos ocupamos de las distintas formas de articulación entre aquellas asociaciones y el activismo de peronistas, anarquistas, socialistas. En este sentido, nuestra intención es poner de relieve las fricciones entre identidades no siempre compatibles, así como destacar los ruidos y desajustes en las articulaciones hegemónicas que enlazaban a aquellas asociaciones. Según conjeturamos, la hegemonía que sobre estos espacios ejercieron las distintas organizaciones políticopartidarias, así como las iniciativas gubernamentales y estatales que sobre aquellos espacios impactaron, no lograron eclipsar por completo los márgenes de independencia, ya que una cuota de iniciativa propia fue irreductible a aquellos deseos de hegemonía. El asociacionismo obrero y popular en todo momento reservó una cuota de poder decisional para sí, en el mayor de los casos vinculado a sus 'intereses particularistas'. En este sentido, aquellos espacios fueron "nidos de la democracia", pero de una democracia no liberal cargada de eventos de beligerancia popular.
\end{abstract}

\section{Palabras clave}

asociacionismo, activación política, clases subalternas, democracia, peronismo

\begin{abstract}
This article proposes an overview of ground-floor political activation. It reviews the diverse forms of workers' associative initiatives that existed in Mar del Plata towards the mid-20th century: unions, libraries, neighbourhood councils. It also deals with the varied relations between the latter and the activism of peronists, anarchists and socialists. The intention here is to show the frictions between sometimes incompatible identities at that time, and to highlight the existing noises and imbalances in the hegemonic articulations between those
\end{abstract}

\footnotetext{
- Una primera versión de esta investigación fue publicada en Omar Acha y Nicolás Quiroga, Asociaciones y política en la Argentina del siglo veinte. Entre prácticas y expectativas, Buenos Aires: Prometeo, 2015. Agradezco los comentarios de Fernando Balbi a la versión que de este artículo presenté en las jornadas Interescuelas de Historia, Mendoza 2013. También agradezco las sugerentes observaciones de la Dr. Mara Petitti a una versión preliminar de este artículo.
}

Esta obra está sujeta a la Licencia Reconocimiento-NoComercial-Compartirlgual 4.0 Internacional de Creative Commons. http://creativecommons.org/licenses/by-nc-sa/4.0/ 


\section{Vida asociativa al ras del suelo}

associations. In my view, the hegemony of diverse political and partisan organisations over these spaces, as well as the governmental and state initiatives that had an impact on these, did not succeed entirely in stopping their independence. Indeed, a quota of 'autonomy' existed in those hegemonic initiatives. Popular and workers' associative initiatives always preserved some independence, generally linked to their 'particularist interests'. In this sense, those spaces were 'nests of democracy'; not of a liberal democracy but one loaded with popular belligerency.

\section{Keywords}

associationism, political activation, subaltern classes, democracy, Peronism 


\section{Agustín Nieto}

\section{Notas introductorias}

En este escrito nos proponemos rastrear los espíritus latentes y manifiestos de 'escisión' que informan las acciones emprendidas por las clases subalternas, lo haremos ensayando un análisis en clave monográfica y microhistórica. El sentido de nuestra indagación es reponer la veta política del accionar plebeyo, intentando escapar a las miradas utilitaristas y economicistas. Dentro del amplio campo de estudios sobre el asociacionismo en la Argentina contemporánea una referencia obligada por su carácter hegemónico son las investigaciones y ensayos realizados en el marco del Programa de Estudios de Historia Económica y Social Americana (PEHESA), entre los años ochenta y la actualidad. Entre otras, la imagen de las asociaciones populares como "nidos de la democracia" fue una figura fundacional del Programa que emergió con fuerza en el contexto de la transición democrática. Sin embargo, el linaje de esta figura reactualizada en los ochenta se remonta a los años cincuenta, en particular a las reflexiones de Gino Germani sobre la participación de las masas populares en la vida política nacional. Entre las condiciones para la integración de las masas populares a la vida política lista "la educación del soberano" no reduciéndola a la instrucción formal sino extendiéndola a la vida diaria de "el hombre común". Éste debía practicar la democracia y la libertad en su existencia personal cotidiana a través de su participación política en la "comunidad local", la cual era entendida como la base de la democracia. En sus palabras, "el ejercicio de los derechos políticos en el ámbito más restringido de esta comunidad que se presenta como una posibilidad mucho más concreta y cercana para la mayoría de la gente". ${ }^{1}$ Asimismo esta reflexión se nutrió de las consideraciones y lecciones que diversos activistas desplegaron en el terreno. Según las palabras de un militante libertario la convivencia en una entidad vecinal constituye de por sí una "labor docente" que introduce a sus integrantes en lo rudimentos de la participación democrática: “... los vecinos ya adultos aprenden [...] a presidir una reunión o asamblea, a redactar un acta, a confeccionar un balance, a emitir ordenadamente su opinión en un debate...".2

En una presentación somera de esta figura podemos decir que los miembros del PEHESA entienden que los "nidos de la democracia" son los escenarios donde los individuos aprenden a ser ciudadanos de una república liberal-democrática. ${ }^{3}$ Asimismo, consideraban que su importancia se acrecentaba en los momentos de gobiernos autoritarios, pues revestían el carácter de reservorios de civilidad democrática. Con el tiempo, este optimismo inicial sobre las bondades de los "nidos" fue matizado, pues se había descubierto que éstos podían ser activos de una forma no democrática. Es decir que podían adaptarse a contextos autoritarios volviéndose

\footnotetext{
${ }^{1}$ Gino Germani. "La integración de las masas a la vida política y el totalitarismo", Cursos y Conferencias VLVIII, n.o 273, 1956, pág. 158.

2 Héctor Woollands. Recuerdos de un militante anarquista, Mar del Plata, Grupo Editor "El Martillo», 1999, págs. 110-111.

3 PEHESA. “¿Dónde anida la democracia?”, Punto de Vista, n. 15, 1982, págs. 6-10.
} 


\section{Vida asociativa al ras del suelo}

menos democráticos, aunque manteniendo, y en ocasiones acrecentando, su activación. Así se llegó a la conclusión que estos nidos no eran inmunes a la burocratización. ${ }^{4}$

Según esta visión, no se puede determinar un momento exacto en la devaluación de la cultura cívico-democrática, aunque sí se puede establecer una inflexión en los escenarios: republicano y democrático para el período 1912-1945 y plebiscitario y estatalista para los años 1945-1955. Desde el '45 y hasta 1983, "la democracia” fue desplazada del imaginario político contemporáneo. A partir de los años sesenta su lugar fue ocupado por la figura de "la revolución". Recién con la victoria electoral de la UCR, y la derrota correspondiente del PJ, en 1983, la sociedad argentina vivió una corta primavera democrática de carácter liberal y republicana. Con esta periodización queda claro que el movimiento peronista impactó negativamente en la ya dificultosa sedimentación de una cultura política democrática, liberal y republicana. Esto porque la tan mentada democratización social por rieles estatales tuvo como costo la degradación del "ciudadano educado" y el desbarranco económico. En este sentido la historiografía política del "primer peronismo" se hermana con la historiografía económica que entiende al peronismo como la causa del declive del "progreso argentino". 5 En ambas el peronismo como populismo no deja de ser un "hecho maldito".6 También aquí la visión procedimentalista y normativa de las prácticas democráticas sostenida por el PEHESA remota su linaje hasta la obra de Germani, quien explícitamente diferencia entre "lo que debería ser la democracia" y las prácticas políticas efectivas bajo el peronismo. ${ }^{7}$

Nuestro ensayo en estas páginas será mirar esos mismos espacios con otras lentes. En este ejercicio nos resistiremos a negar el carácter democrático a las formas "movimientistas" de participación y activación. Desde esta perspectiva, saltarse los procedimientos de las instituciones representativas e interpelar al estado desde las calles, las plazas, los piquetes, las fábricas, será entendida como una forma otra de practicar la democracia por parte de las clases subalternas.

El artículo está estructurado en dos apartados. En el primero nos ocuparemos de analizar la vida política barrial, recalando en aquellas experiencias que nos permitan acercarnos a su pulso cotidiano. En el segundo apartado buscaremos examinar el activismo político en el mundo obrero sindical, tomando para su abordaje aquellos eventos que nos habiliten una mirada a ras del suelo. En las notas

\footnotetext{
${ }^{4}$ Luciano De Privitellio y Luis Alberto Romero. "Organizaciones de la sociedad civil, tradiciones cívicas y cultura política democrática: el caso de Buenos Aires, 1912-1976", Revista de Historia 1, n. ${ }^{\circ}$ 1, 2005, págs. 11-59.

5 Véase en particular Carlos Federico Díaz Alejandro. Ensayos sobre la historia económica argentina, Buenos Aires, Amorrortu, 1975 y Juan José Llach. "El plan pinedo de 1940, su significado histórico y los orígenes de la economía política del peronismo”, Desarrollo Económico 23, n. 9 92, 1984, págs. 51558.

${ }^{6}$ Omar Acha y Nicolás Quiroga. El hecho maldito: conversaciones para otra historia del peronismo, Rosario, Prohistoria, 2012.

7 Germani. "La integración de las masas a la vida política y el totalitarismo”, 161.
} 


\section{Agustín Nieto}

finales nos proponemos reflexionar sobre algunos marcos conceptuales que consideramos problemáticos a la hora de dar cuenta de la complejidad de sentidos que disparan las acciones plebeyas.

\section{La vida asociativa barrial en los márgenes del pago}

En este apartado nos detendremos en algunos eventos que consideramos ilustrativos de los perfiles de la vida asociativa en los barrios populares marplatenses hacia mediados del siglo XX. Consideramos pertinente advertir que desde nuestra perspectiva analítica lo barrial y popular no solo no son excluyentes de lo obrero y fabril sino que se complementan habilitando una mirada más compleja del asociacionismo practicado por las clases subalternas.

Durante los años peronistas el suelo asociativo de la aldea estuvo en constante burbujeo. Con esta afirmación no queremos ningunear situaciones similares en un momento previo o posterior, solo pretendemos exponer los resultados de nuestra exploración sobre el terreno de la activación popular y obrera para aquel período. Mantenemos las hipnóticas fronteras del "peronismo clásico" en nuestra periodización para entrar en diálogo con un campo de estudios que se consolidó con aquellas coordenadas temporales, las cuales son extremadamente porosas. Otra estimulación para abordar aquellos años es la intensa presencia aldeana de activistas libertarios vinculados por fuertes lazos generacionales. Asimismo, la posibilidad de revistar la emergencia de diversas asociaciones peronianas en su momento fundacional es una tercera motivación para dibujar aquellas fronteras temporales, que nunca dejaran de ser arbitrarias. Todo esto en una aldea que experimentó grandes cambios en su morfología social, económica, política y cultural. ${ }^{8}$ En el transcurso de una década la población del Partido de General Pueyrredón prácticamente se duplicó. ${ }^{9}$

En este apartado nos ocuparemos de desagregar del universo del activismo y asociacionismo obrero y popular aquellos eventos que están vinculados a la dimensión barrial de aquel acontecer. Asimismo, de este último desagregado, nos detendremos en aquellos sucesos y trayectorias que se muestran más intrincadas y densas. Una de estas "historias mínimas" con la cual elegimos despuntar este relato es la referida al barrio "El Martillo". El principal insumo de nuestra "reconstrucción" es la reseña histórica sobre este barrio escrita por el autor de Recuerdos de un Militante Anarquista. ${ }^{10}$

\footnotetext{
${ }^{8}$ Ana Núñez. Morfología social de Mar del Plata (1874-1990), Tandil: Grafikart, 2000; Nicolás Quiroga. "Cambios sociales bajo conflictos políticos en Mar del Plata, 1945- 1955. Algunos problemas e interpretaciones", en Pasado y Presente de la Mar del Plata Social / Coloquio 1, Mar del Plata, eudem, 2005.

${ }^{9}$ Según los datos censales, la población del partido pasó de 123.811 habitantes en 1947 a 224.824 habitantes en 1960.

${ }^{10}$ Héctor Woollands. Reseña histórica del Barrio Florencio Sánchez, Mar del Plata, Sociedad de Fomento Florencio Sánchez, 1990.
} 


\section{Vida asociativa al ras del suelo}

Según nos cuenta Woollands, los loteos de la zona conocida como "El Martillo", nombre de una vieja estancia del lugar, comenzaron hacia fines de la década del cuarenta. Momento en el cual distintas familias obreras de bajos recursos se fueron embarcando en la "aventura finisemanal de 'levantar el rancho'". A medida que esta zona "periférica" de la aldea se fue poblando distintos comercios fueron radicándose: almacenes, carnicerías, panaderías, "despacho de bebidas", y otros "boliches".11 En esos primeros momentos el villerío carecía de energía eléctrica, calles asfaltadas y otros servicios. El colectivo pasaba solo dos veces al día (a la mañana y a la tarde). Unos años más tarde, en 1952, la empresa de transportes, respondiendo a la demanda de lxs vecinxs, aumentó la frecuencia y amplió el recorrido, conectando este novel poblado con el primero de la zona, el barrio "17 de Octubre". En esos primeros años los fines de semana y feriados

(...) toda la zona era teatro de una febril actividad. Levantando paredes, revocando o techando, en cada manzana se veían incipientes obras en la que trabajaban afanosamente improvisados albañiles, adolescentes imberbes y mujeres haciendo de peones y al mediodía se esparcía por toda la comarca el incipiente olorcito del churrasco que sería el almuerzo de la cuadrilla familiar. ${ }^{12}$

Toda esta "aventura", en contraste a lo que presupone la lectura pehesiana, no fue vivida como un proceso de movilidad ascendente sino como un "desplazamiento" de los "pobretes" por los "más pudientes" hacia zonas "semidesiertas" de la aldea. ${ }^{13}$ Es interesante advertir que el concepto de "movilidad social" tiene una fuerte carga "economicista" y "objetivista" que deberíamos revisar. En este sentido se torna pertinente preguntarnos si las familias "desplazadas" hacia los márgenes del ejido urbano no sintieron dañado su "derecho a la ciudad". Derecho que siguió pulsando en la vena fomentista de las nuevas barriadas.

Ya en vísperas del techo propio, el poblado comenzó a manifestar sus inquietudes en torno a algunas "necesidades básicas": luz eléctrica, educación, pasos de piedra, asfalto, medios de transporte, servicio de correspondencia, teléfonos, agua potable, esparcimiento, salas de primeros auxilios, etc. Este fajo de demandas fue estimulando el activismo barrial a la vez que el despertar de una multiplicidad de asociaciones vecinales con un grado alto de articulación, no exenta de algunos cortocircuitos. En ocasiones las nuevas entidades se solapaban con las ya existentes. A lo largo de aquellos años los pobladores de "El Martillo" impulsaron la creación de clubes deportivos, sociedades de fomento, unidades básicas, cooperativas, bibliotecas, cooperadoras escolares, clubes de madres, guarderías, clubes de exalumnos, salas de primeros auxilios, entre otras. La fundación y sostenimiento de cada una de estas entidades requirió la participación activa de un grupo importante del poblado, grupo que a su vez buscaba articular con sindicatos, partidos,

\footnotetext{
11 Ídem, pág. 7.

12 Ídem, pág. 8.

13 Ídem, pág. 7.
} 


\section{Agustín Nieto}

corporaciones patronales, agencias estatales, etc., con el objetivo que sus demandas llegaran expeditivamente a buen puerto. Este movimiento articulatorio supo de conflictos y tensiones. Tomemos por caso la demanda de dos escuelas para la zona impulsada en distintos momentos por los vecinos de "El Martillo".

Luego de varias reuniones y peticiones, el Ministerio de Educación de la Provincia de Buenos Aires resolvió la creación de la Escuela 37. Este organismo estatal se responsabilizaba de los costos de mantenimiento y de los salarios docentes, pero el edificio escolar fue construido por "el vecindario de ese populoso sector" con la contribución municipal de 5 mil pesos, en un terreno donado a ese fin por una firma dedicada a las operaciones inmobiliarias y entregado posteriormente al ministerio. ${ }^{14}$ El edificio, que disponía de dos aulas con capacidad para 30 alumnxs cada una, fue inaugurado con la presencia del ministro Avanza. La escuela contó en su primer año de existencia con 70 inscriptos. ${ }^{15}$ Pero el vecindario siguió creciendo y la necesidad de otra escuela se hizo presente.

La aspiración de una nueva escuela primaria se fue acicateando a medida que un mayor número de niños del barrio "El Martillo" alcanzaban la edad escolar. Desde ese momento algunos vecinos comenzaron a gestionar el pedido ante las autoridades gubernamentales. Su tenacidad e insistencia dieron resultados satisfactorios para la barriada: en 1954, con la presencia de José A. Cavallo (intendente municipal peronista), fue habilitada la Escuela 45 "Bernardino Rivadavia", ubicada en calle Génova 5267. Al igual que en la experiencia previa, este resultado fue producto de una mixtura entre dos voluntades, la de lxs "martillenses" y la gubernamental-estatal. La infraestructura edilicia para el funcionamiento de la escuela la brindó el vecino Eloy Buenahora (obrero municipal, recolector de residuos, militante peronista y presidente de la Sociedad de Fomento del "Barrio 17 de Octubre") al prestar el salón del cual disponía, mientras las autoridades gubernamentales dispusieron los recursos para la designación del personal docente, dos maestras (Julia Marino y Tulia Larrea) y un maestro (Román González). Cada uno tenía a cargo dos grados, cubriendo así la totalidad de seis. En ese momento la matrícula rondaba los 200 alumnos, pero rápidamente el salón fue quedando chico, sobreviniendo la necesidad de mayores comodidades.

De forma conjunta los vecinos y el municipio se pusieron en campaña para encontrar un lugar dónde construir un edificio escolar. El terreno fue prontamente ubicado y en junio de 1955 fue colocada la piedra fundacional. En la nota periodística que reseñaba el evento se aclaraba que hasta el momento la Escuela 45 estaba funcionando en un "local provisorio, que resulta insuficiente para las necesidades crecientes del elevado número de niños en edad escolar residentes [en el barrio]". En la misma nota se daba cuenta de otra demanda de lxs vecinxs del barrio "El Martillo". Estxs estaban peticionando a las autoridades municipales una sala de primeros auxilios, que consideraban "indispensable para los numerosos pobladores

${ }^{14}$ La Capital, 22/04/1951.

${ }^{15}$ La Capital, 04/04/1951. 


\section{Vida asociativa al ras del suelo}

de ese paraje, habitado por familias de modestos trabajadores, los cuales deben cubrir largas distancias para dirigirse a los establecimientos asistenciales del centro". ${ }^{16}$ Sin embargo, las gestiones se vieron truncadas, momentáneamente, por el derrocamiento del gobierno peronista en septiembre de 1955.

Antes de pasar a otras experiencias barriales nos parece interesante comentar algo sobre la trayectoria de Héctor Woollands como activista destacado en el ámbito del fomentismo martillense. Desde su llegada a Mar del Plata en 1939, aparte de su labor barrial, se destacó como militante gremial y político. En esta última dimensión, su identidad y militancia orgánica se desplegó al interior de las fronteras anarquistas, pues fue un destacado dirigente de la FACA, primero, y de la FLA, después. Este solapamiento de identidades (anarquista /fomentista) nos permite revisar la imagen de la incapacidad adaptativa de los libertarios a la cultura barrial. ${ }^{17}$ Su militancia libertaria y "antiperonista" no impidió que en cuestiones de mejoramiento barrial presionara, junto a fomentistas identificados con el movimiento peronista (Eloy Buenahora), a los distintos intendentes y comisionados. En sus memorias Héctor Woollands se refiere a Eloy Buenahora en los siguientes términos:

(...) sin pensar en la inmortalidad y ni siquiera en el reconocimiento de sus propios vecinos este hombre noble y silencioso, este trabajador oscuro e ignorado, cumplía con un imperativo de su conciencia: Trabajar honradamente todos los días y brindar su ayuda al prójimo en la medida de sus posibilidades. Un ejemplo de conducta solidaria sin ninguna especulación, sin aspirar a obtener votos para una candidatura política ni a ganar adeptos para una secta religiosa, nada de eso. Hacer el bien porque sí nomás, como un estilo de vida fructífera y fecunda.18

Múltiples fueron las experiencias y trayectorias como las precedentemente reseñadas. En el barrio se constelaban y articulaban diversas asociaciones como Sociedades de Fomento, Bibliotecas, Clubes Deportivos, Cooperadoras Escolares, entre otras. Al decir de Woollands "bajo el denominador común de entidades populares se involucra a sociedades de fomento, juntas barriales, cooperadoras escolares, sindicatos obreros, clubes de barrio, cooperativas de crédito, sociedades de socorros mutuos, salas de primeros auxilios y muchas más...". ${ }^{19}$ No solo que desde estas asociaciones se buscaba y/o eran objeto de vínculos con las organizaciones político-partidarias, sino que muchos de sus activistas eran a su vez militantes políticos. Así pasó en las sociedades de fomento de Gral. San Martín, La Perla, San José, Santa Mónica, Plaza Mitre, Punta Mogotes, San Juan, Bernardino

\footnotetext{
${ }^{16}$ La Capital, 07/06/1955.

17 "Los libertarios se adaptaron mal a esta política estatal de concesiones y a la cultura barrial, que centraba la atención en reivindicaciones de carácter territorial, fomentismo, y dependía del diálogo permanente con las autoridades municipales" Juan Suriano, Anarquistas. Cultura y política libertaria en Buenos Aires, 1890-1910, Buenos Aires: Ediciones Manantial, 2001.

18 Woollands. Reseña histórica del Barrio Florencio Sánchez, pág. 9.

19 Woollands. Recuerdos de un militante anarquista, pág.121.
} 


\section{Agustín Nieto}

Rivadavia, San Carlos, 9 de Julio, Cerrito, Parque Gral. Roca, Fortunato de la Plaza, Nueva Pompeya, Villa Primera, Estación Chapadmalal, entre otras.

Esta yuxtaposición de identidades y roles la pudimos reconstruir parcialmente a partir de la confección de una base de datos relacional, donde ingresamos a los integrantes de las distintas organizaciones educativas, de fomento, deportivas y partidarias aparecidas en la prensa periódica. También nos nutrimos de los nombres recolectados en sus respectivas investigaciones por Mara Petitti, Silvana Ferreyra y Nicolás Quiroga, cuyo acervo documental fue del mismo tipo que el nuestro. ${ }^{20}$ El cruce entre la inscripción partidaria y la barrial de un grupo de vecinos nos permite imaginar un grado no desdeñable de solapamiento entre activismo barrial y político. En una muestra al azar sobre la composición de distintas entidades barriales y partidos políticos discriminamos a aquellos individuos que además de una identificación política partidaria tenían una participación múltiple en organizaciones barriales. El resultado fue el siguiente:

\begin{tabular}{|c|c|c|}
\hline Nombres & Org. Barrial & $\begin{array}{c}\text { Org. } \\
\text { Política }\end{array}$ \\
\hline Cagstaña, Alberto & 2 & 1 \\
\hline Catalano, Manuel & 2 & 1 \\
\hline Cotado, Santiago & 2 & 1 \\
\hline Falcone, Luis A. & 2 & 1 \\
\hline Fernández, José & 2 & 1 \\
\hline Fernández, Manuel & 2 & 1 \\
\hline González, Rufino & 2 & 1 \\
\hline Ivars, Eduardo & 2 & 1 \\
\hline Lattes, Alfredo & 2 & 1 \\
\hline Marini, Federico & 3 & 1 \\
\hline Martín, José A. & 2 & 1 \\
\hline Mendoza, Víctor I. & 2 & 1 \\
\hline Montalto, Armando & 2 & 1 \\
\hline Mora, Narciso & 2 & 1 \\
\hline Nocelli, Antonio A. & 2 & 1 \\
\hline Pereyra, Juan Manuel & 2 & 1 \\
\hline Ríos, Angel & 2 & 1 \\
\hline Rodríguez, Juan Antonio & 3 & 1 \\
\hline Romero, Manuel & 2 & 1 \\
\hline Rufino, Rodolfo & 2 & 1 \\
\hline Souza, Isidro & 2 & 1 \\
\hline Ventura, Concepción & 2 & 1 \\
\hline Viti, Lorenzo & 2 & 1 \\
\hline
\end{tabular}

Asimismo pudimos identificar la convivencia, dentro de una misma entidad barrial, de activistas adscriptos a distintas organizaciones políticas. Como podemos ver en la muestra presentada en el Cuadro 2, las comisiones directivas de las

\footnotetext{
${ }^{20}$ Silvana Ferreyra. "Socialismo y antiperonismo: el Partido Socialista Democrático. Transformación partidaria y dinámica política en tiempos de proscripción, Provincia de Buenos Aires, 1955-1966", Tesis Doctoral, UNMdP, 2012; Mara Petitti, "La educación primaria durante el peronismo. La experiencia de la provincia de Buenos Aires, 1946-1955", Tesis Doctoral, UNMdP, 2014; Nicolás Quiroga, "La dimensión local del Partido Peronista. Las unidades básicas durante el primer peronismo, Mar del Plata, 1946-1955”, Tesis Doctoral, UNMdP, 2010.
} 
cooperativas escolares, sociedades de fomento y clubes deportivos estuvieron compuestas a un mismo tiempo por anarquistas, socialistas, peronistas y radicales.

Cuadro 2: Convivencia de activistas peronistas, anarquistas, socialistas y radicales en entidades barriales marplatenses durante los años 1943-1955.

\begin{tabular}{|c|c|c|c|c|}
\hline $\begin{array}{c}\text { COMPOSICIÓN DE LAS } \\
\text { ENTIDADES BARRIALES }\end{array}$ & ANARQUISTA & PERONISTA & RADICAL & SOCIALISTA \\
\hline Coop. Escuela 29 & & 1 & 1 & 3 \\
\hline Alonso, Antonio & & & & $\mathrm{x}$ \\
\hline González, Andreu & & & $\mathrm{x}$ & \\
\hline Hernandez, José & & & & $\mathrm{x}$ \\
\hline Martín, José A. & & & & $\mathrm{x}$ \\
\hline Souza, Isidro & & $\mathrm{x}$ & & \\
\hline Coop. Escuela 16 & & 3 & & 2 \\
\hline Barroso, Gabriel & & & & $\mathrm{x}$ \\
\hline Catalano, Manuel & & $\mathrm{x}$ & & \\
\hline Gómez, Nicanor I & & $\mathrm{x}$ & & \\
\hline Inda, Jorge & & & & $\mathrm{x}$ \\
\hline Quinteros, Ángel & & $\mathrm{x}$ & & \\
\hline Mora, Narciso & & & & $\mathrm{x}$ \\
\hline Soc. Fomento Villa Primera & & 1 & & 1 \\
\hline Martín, José A. & & & & $\mathrm{x}$ \\
\hline Souza, Isidro & & $\mathrm{x}$ & & \\
\hline Soc. Fomento Cerrito y San Salvador & 1 & 1 & & \\
\hline Cagstaña, Alberto & & $\mathrm{x}$ & & \\
\hline Ivars, Eduardo & $\mathrm{x}$ & & & \\
\hline Club Atlético Unión & & 1 & & 1 \\
\hline Grasso, Antonio & & & & $\mathrm{x}$ \\
\hline Rodríguez, Juan Antonio & & $\mathrm{x}$ & & \\
\hline Club Atlético Aldosivi & & 1 & & 1 \\
\hline Cotado, Santiago & & $\mathrm{x}$ & & \\
\hline Marini, Federico & & & & $\mathrm{x}$ \\
\hline
\end{tabular}

De esta forma el entramado barrial se veía continuamente tensionado por identidades unas veces cooperativas otras antagónicas, pero nunca perdía por completo la capacidad de movilizarse en procura de mejoras para el conjunto del vecindario.

Otro ámbito de tramitación de tensiones, copiando los ademanes del procedimentalismo liberal-republicano, fueron los procesos electorales en las sociedades de fomento. A lo largo de los años bajo estudio muchas fueron las "juntas promotoras" y "comisiones provisorias" que dieron lugar a la fundación y refundación de entidades vecinalistas. También fueron muchos los procesos electorales donde compitieron dos listas o más. Así sucedió en la Sociedad de Fomento "San José" (donde, en 1954, compitieron dos listas) ${ }^{21}$, por tomar un ejemplo del período abordado. ${ }^{22}$ Asimismo hubo procesos electorales que no copiaban el sistema de lista, eligiendo las autoridades en el marco de asambleas

\footnotetext{
21 El Atlántico, 26/02/1954.

22 El fomentismo marplatense fue abordado para el período 1946-1955 por Quiroga. "La dimensión local del Partido Peronista. Las unidades básicas durante el primer peronismo, Mar del Plata, 19461955".
} 


\section{Agustín Nieto}

generales (a mano alzada o anotando nombres en un papelito). Los cargos se cubrían con los asociados más votados.

Queda hacer una breve mención a las asociaciones eminentemente políticopartidarias en las barriadas de la aldea marplatense. El mitin político en los barrios fue un recurso trasversal a todas las fuerzas políticas: anarquistas, socialistas, comunistas, conservadores, peronistas, radicales. Hacia fines del año 1945, la Junta de Acción Socialista organizó un acto público en el barrio puerto. ${ }^{23}$ Semanas más tarde el Comité Electoral del Centro Socialista de Mar del Plata desarrolló una nueva actividad en el barrio puerto, organizó una conferencia pública en la intersección de las calles Edison y 12 de octubre. Por su parte, esa misma semana el Comité local de la UCR también realizó un acto público en el barrio puerto, en la intersección de las calles 12 de octubre y Figueroa Alcorta. ${ }^{24}$ En el marco de la conmemoración de los mártires de Chicago del año 1948, el Partido Socialista realizó una serie de mítines, siendo uno de ellos en el barrio puerto. Según informaron en su prensa partidaria, el mismo se desarrolló el 1ํo de mayo a las 10 de la mañana en la intersección de las calles Posadas y 12 de octubre. Los oradores fueron Luis C. Príncipi, Jaime Adolfo Guper y Rómulo Etcheverry. ${ }^{25} \mathrm{Al}$ año siguiente las calles del puerto volvieron a ser escenario de nuevas concentraciones. La Unidad Básica Peronista de Independencia y Brown llevó adelante en la intersección de las calles 12 de Octubre y Edison un acto al cual asistió un "numeroso público". 26

El asiento "físico" en los barrios fue otro recurso común, con la fundación de centros, comités, agrupaciones, locales partidarios, unidades básicas, entre otras entidades. Estas últimas proliferaron en las coyunturas electorales durante los años de gobierno peronista. Un recorrido raudo por la prensa local nos permite darnos una idea del grado de activación que las UB desarrollaron las barriadas marplatenses. También nos proporciona una imagen sobre las múltiples actividades proselitistas que se desplegaron en sus marcos más allá de las coyunturas electorales. Entre otras podemos mencionar la "Gran Fiesta de Camaradería" organizada por la UB de calle Francia no 2054 presidida por Agustín Navone, quién aparte de haber sido un destacado dirigente peronista se desempeñó como Secretario General de la Federación Gremial Laborista y asesor de distintas Juntas Vecinales. El evento se organizó con motivo de cumplirse el primer aniversario de la entidad, que en 1949 había sido fundada en una asamblea donde participaron 800 afiliados de un total de 1300 inscriptos. ${ }^{27}$ Por otra parte, una actividad común a todas las UB fue la cotidiana atención a los afiliados y simpatizantes, como por ejemplo la realizada por la UB del Puerto. ${ }^{28}$ Como señala Nicolás Quiroga, su

\footnotetext{
${ }^{23}$ El Puerto, 08/12/1945.

${ }^{24}$ El Puerto, 26/01/1946.

${ }^{25}$ El Trabajo, 03/05/1948.

${ }^{26}$ El Puerto, 25/11/1949.

${ }^{27}$ El Atlántico, 08/09/1950.

${ }^{28}$ El Puerto, 25/11/1949.
} 


\section{Vida asociativa al ras del suelo}

activación a ras del suelo fue fundamental para la vida del PP. ${ }^{29}$ En cierta forma, las UB son a las elites del PP lo que las clases subalternas son a la elite estatal peroniana: un elemento plebeyo indomesticable pero imprescindible. ${ }^{30}$

\section{El activismo sindical en la aldea}

En este apartado buscamos dar cuenta de las aristas que presenta el análisis de la vida sindical a ras del suelo en una ciudad portuaria del sudeste bonaerense durante los años peronistas. A partir de la reconstrucción de microhistorias y trayectorias aldeanas en el mundo sindical marplatense tenemos la intención de reponer su carácter archipelágico.

Comenzaremos a transitar este segundo apartado desde las experiencias asociativas que entrelazó la Unión Obrera Local, fundada por un núcleo de activistas libertarios (FACA) en agosto de 1940, entre lxs que se encontraba Héctor Woollands. A parte de una densa constelación de sindicatos, la UOL-Casa del Pueblo articuló en torno suyo un teatro y una ya longeva biblioteca: la Biblioteca Popular Juventud Moderna (BPJM). Estamos convencidos que esta última es un excelente blanco para arriesgar una calibración de las hegemónicas interpretaciones pehesianas fundadas en su concepto de "sectores populares".

La BPJM fue fundada en noviembre de 1911 por un grupo de obreros anarquistas con el nombre de "Sociedad Instructiva y Recreativa Juventud Moderna". El carácter obrero de sus s no era una extrañeza como tampoco lo fue su persistente vínculo con las entidades sindicales. Según Woollands, son pocas las bibliotecas del interior del país que no hayan sido creadas por un grupo de trabajadores organizados sindicalmente. "De ahí que resulte imposible hacer la historia de las bibliotecas populares sin que al mismo tiempo se escriba, siquiera parcialmente, la historia de los sindicatos obreros en el interior del país". ${ }^{31}$ El salón de la BPJM fue escenario de distintos eventos como conferencias educativas, veladas literarias, festivales cinematográficos, actos artísticos, cuadros filodramáticos realizados por aficionados. ${ }^{32}$ Pero sobre todo fue el recinto de las múltiples asambleas y reuniones obreras. Distintos sindicatos tuvieron su sede en la Biblioteca y allí se reunían para debatir y resolver sus problemas gremiales.

\footnotetext{
${ }^{29}$ Nicolás Quiroga. "Comunidad y carisma: continuidades en las modalidades organizativas de las unidades básicas peronistas, 1945-1960”, Buenos Aires: mimeo, 2012.

30 Omar Acha. "Sociedad civil y sociedad política durante el primer peronismo", Desarrollo Económico, n. ${ }^{174,2004}$, págs. 199-230.

${ }^{31}$ Héctor Woollands. Notas para la historia de la Biblioteca Popular Juventud Moderna, Mar del Plata, Ediciones BPJM, 1990, págs. 7-8.

${ }^{32}$ Entre las obras que se presentaron durante los primeros años Woollands menciona "Juan José" de Dicenta, "Tierra baja" de Guimerá, "La Fragua" de Dicépolo, "La montaña de las brujas" de Sánchez Gardel, "La Huelga" de Foppa, "Alma Gaucha" de Giraldo, El Sargento Palma" de Coronado, "Los Muertos" de Sánchez, "Silvio Torcelli" de Mertens, todos bajo la dirección de Francisco Cárpena.
} 


\section{Agustín Nieto}

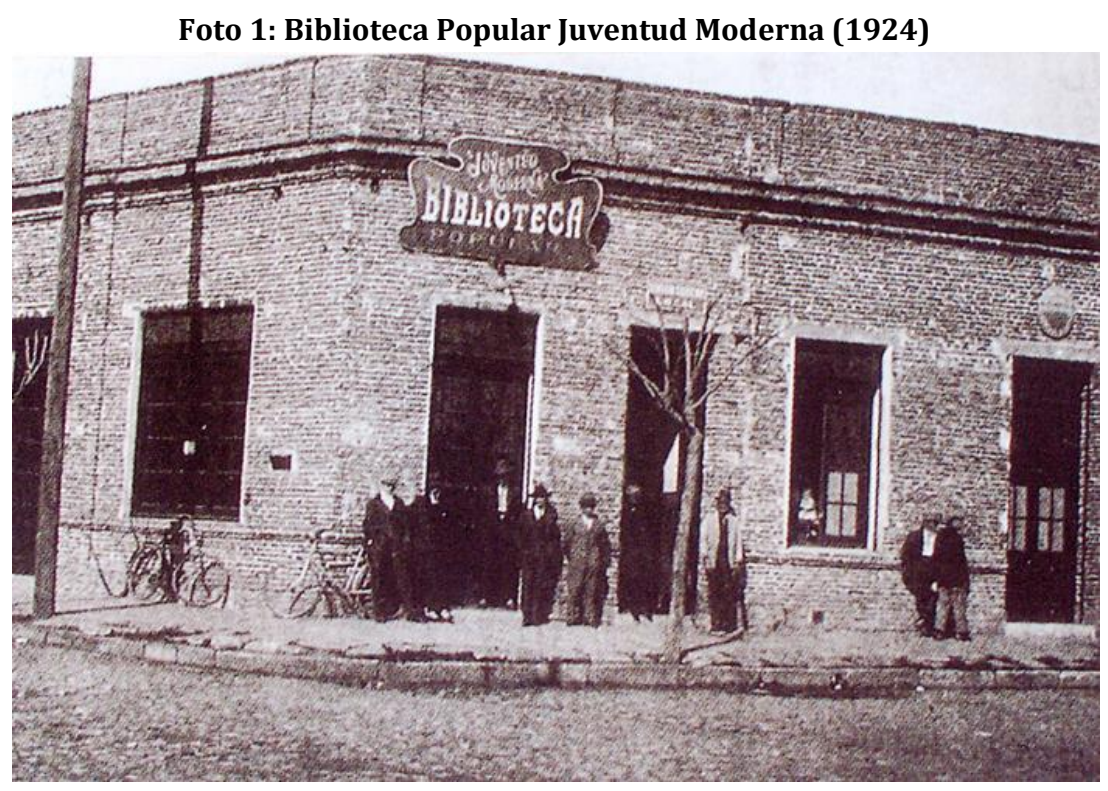

Fuente: Fotos de Familia, diario La Capital (online).

En una reseña aparecida en las páginas de La Protesta se decía que la BPJM constaba de un edificio de "regulares dimensiones, de aspecto sencillo y sobrio, acusa, con su frente sin revocar, pero en perfectísima condiciones de solidez, todas las características que le son propias a los locales obreros. Y es que en el mismo tienen su secretaría". 33

Sostener la Biblioteca implicó desarrollar actividades que significasen un ingreso seguro a sus arcas, para lo cual se organizaban fiestas, romerías, kermeses, venta de bonos solidarios, rifas, entre otras. También contó con aportes de la municipalidad (durante las intendencias socialistas), de comerciantes e industriales. Pero sobre todo se sostuvo con el aporte mensual de los sindicatos que allí tenían su sede. En la medida que las actividades fueron multiplicándose y la actividad sindical fue proliferando, el espacio físico del que se disponía fue estrechándose. De esta forma, hacia fines de 1940 surgió la necesidad de ampliar la sede de la BPJM. Las reformas se realizaron con donaciones de dinero y trabajo solidario por parte de los obreros adheridos a la novel UOL. Fue en ese momento que un grupo de obreros y miembros de la biblioteca crearon la "Agrupación Artística Amigos del Arte".34

Hacia fines de 1947, la tensa relación que los gremios adheridos a la UOL mantenían con el gobierno y los sindicatos peronistas terminó con una derrota de los primeros y la clausura de la UOL-Casa del Pueblo. Esta clausura afectó también a la BPJM que permaneció inhabilitada durante 10 meses. Tanto la interrupción como la posterior vigilancia policial lejos estuvieron de segar la vida de esta asociación.

\footnotetext{
${ }^{33}$ La Protesta, enero de 1941.

34 "Vía Crucis" de Ruiz Huidobro, "Los Mirasoles" y "Amor de Otoño" de Sánchez Gardel, "Hermano Lobo" e "Hijos del Pueblo", de González Pacheco, "Bendita Seas" de Novión, "Tierra Arada" de Castro, "El Secreto" de Sender, fueron las obras que en los primeros años de la década del cuarenta interpretaron lxs integrantes de la Agrupación Artística Amigos del Arte" Woollands, Notas para la historia de la Biblioteca Popular Juventud Moderna.
} 


\section{Vida asociativa al ras del suelo}

Una actividad que se realizaba todos los años, tanto durante los días peronistas como posteriormente, fueron los picnics a la canasta. Estos eventos reunían anualmente a más de 150 personas vinculadas a la BPJM. Durante esa jornada los asistentes desarrollaban, entre otros divertimentos, la elección de la "Animadora de la Fiesta". Según reseña Woollands se prefería "animadora" a "reina", por el tinte monárquico de este último término. Sin embargo, no era ésta la única razón, también daba cuenta de una forma de resistencia a la popularizada elección de la "reina del trabajo" en los gremios hegemonizados por peronistas. La elección de la "Animadora de la Fiesta" también se presentaba como un escenario propicio para entrenarse en los rudimentos de la participación política, replicando la imagen del "nido" dentro del "nido" (de la democracia). Al principio de la jornada se colocaba una urna y se repartían sobres entre "los muchachos" para que eligieran a su candidata entre las chicas asistentes. Hacia el final del picnic se cerraba la votación y se realizaba el escrutinio. Así presentado "parecía un juego demasiado inocente para que pudiera suscitar interés. Pero (...) a medida que iba avanzando el día y se iban acumulando los sobres con sus tarjetas e iban perfilando a la posible ganadora, relegando a otras candidatas se originaba una puja". Esto motivaba la formación de "grupos de propulsoras de una y otra aspirante", los cuales improvisaban campañas adquiriendo grandes cantidades de votos. ${ }^{35}$ Pese a su explicita y fundamentada diferenciación entre "animadora" y "reina", ambos formatos tenían una fuerte carga patriarcal.

A principios de abril de 1951 la BPJM obtuvo la personería jurídica que reconocía su condición de sociedad civil, mediante el decreto $\mathrm{n}^{\circ} 6005$. A partir de ese momento comenzó a beneficiarse del subsidio otorgado por la Comisión Protectora de Bibliotecas Populares, tanto durante los gobiernos peronistas como con posterioridad. ${ }^{36}$

Durante todo el período bajo estudio la Comisión de Cultura de la BPJM impulsó diversos ciclos de conferencias. Durante el mes de septiembre de 1946, el Dr. Rómulo M. Etcheverry disertó sobre "Higiene del Trabajo Industrial”. ${ }^{37}$ En 1951 Víctor Fuentealba disertó sobre "La Liberación Humana", según el informe de la División de Orden Público asistieron a dicha conferencia 55 personas. ${ }^{38}$ Pocos meses más tarde la biblioteca organizó otra conferencia, en esta ocasión sobre "Medicina y Cooperativismo" a cargo de Julio M. Martin. ${ }^{39}$ Al siguiente año, en el marco de un nuevo ciclo de conferencias, ofreció una charla titulada "Comentando a Martín

\footnotetext{
35 Ibíd.

36 Para profundizar sobre esta temática véase Flavia Fiorucci. "La cultura, el libro y la lectura bajo el peronismo: El caso de la comisión de bibliotecas populares”, Desarrollo Económico, 48, n. ${ }^{0} 192$, págs. 543-56.

37 El Puerto, 28/09/1946.

38 DIPPBA, Mesa DS, Legajo N³, f. 11, 15/09/1951.

39 DIPPBA, Mesa DS, Legajo N 3, f. 13, 08/03/1952.
} 


\section{Agustín Nieto}

Fierro" el militante anarquista Luis Woollands. ${ }^{40}$ Hacia fines del año 1954 Héctor Woollands ofreció una conferencia sobre "José Martí. Una Vida y Una Pasión".41

En 1950 El Atlántico publicó un breve informe del movimiento que se registró en la BPJM entre enero de 1949 y marzo de 1950. La nota nos permite hacernos una somera imagen de la vida interna de esta entidad en los años peronistas. En esos quince meses fueron 2.708 los lectores que retiraron a domicilio material de la biblioteca (270 mujeres y 1438 varones), 271 de los cuales fueron estudiantes. Otrxs 539 lectores consultaron libros en la biblioteca. En ese lapso la BPJM registró 35 nuevos socios. También se compraron 300 nuevos volúmenes y se recibieron 95 obras en carácter de donaciones. ${ }^{42}$

Pasemos a sondear las experiencias protagonizadas por la UOL. Desde su fundación (1940) hasta su clausura (1947), la UOL desplegó una intensa activación gremial. La tasa de sindicalización creció, los sindicatos adheridos se multiplicaron así como las huelgas por estos impulsadas. También fue significativa la cantidad de huelgas generales de solidaridad que declaró la UOL en apoyo a trabajadores en conflicto con sus patronales. Las asambleas y reuniones fueron de carácter cotidiano como también lo fueron los conflictos en los lugares de trabajo. Densa fue la red de delegados que la UOL logró articular. Intensas fueron las campañas contra la carestía de la vida. En todo este despliegue los comunicados en la prensa comercial, los volantes y panfletos, el periódico de la UOL, entre otros medios de difusión y propaganda, fueron de suma relevancia. La UOL también supo impulsar actividades recreativas, en particular picnics, un importante ámbito de sociabilidad obrera. En el plano de "la cultura", además de auspiciar a la BPJM, promovió la creación del Teatro Popular de la UOL. Y en la dimensión de "formación" promovió la creación de la Peña de Estudios Sindicales y Sociales.

Hasta aquí un breve repaso de la activación anarquista en el mundo obrero, como una de las derivas del "campo antiperonista". Veamos ahora las derivas del activismo peronista en el mundo obrero. Vale aclarar que el análisis de estas últimas tiene como uno de sus objetivos poner en discusión la difundida imagen sobre el carácter regimentador y heterónomo del "sindicalismo peronista".

La Federación Gremial Laborista primero y la CGT más tarde le disputaron a la UOL la hegemonía sobre el movimiento obrero marplatense replicando la capilarización de sus formatos organizativos. Luego de algunos fracasos, los enfrentamientos terminaron favoreciendo al bando peronista, que hacia 1948 se hizo con la conducción del movimiento obrero local. Esta hegemonía no supuso la extinción de la UOL, que se reorganizó en 1955, ni una mengua en el activismo obrero. La cantidad de reuniones, asambleas y elecciones gremiales se multiplicó al

\footnotetext{
40 DIPPBA, Mesa DS, Legajo N³, f. 14, 05/10/1953.

41 DIPPBA, Mesa DS, Legajo N³, f. 16, 29/11/1954.

42 El Atlántico 27/06/1950. Sobre lxs lectores de la BPJM puede consultarse Elisa Pastoriza. Los trabajadores de Mar del Plata en vísperas del peronismo, Buenos Aires: Centro Editor de América Latina, 1993; Nicolás Quiroga. "Lectura y política: los lectores de la Biblioteca Popular Juventud Moderna de Mar del Plata, fines de los años treinta y principios de los cuarenta", Anuario IEHS, n. ${ }^{\circ} 18$, 2003, págs. 449-74.
} 


\section{Vida asociativa al ras del suelo}

igual que la conflictividad laboral. Las demandas en el fuero laboral es una "muestra" de esto último. Asimismo, en el derrocamiento de Perón no significó en la ciudad la desarticulación absoluta del gremialismo peronista ni el afianzamiento definitivo del sindicalismo antiperonista. Desde su conformación la CGT se mostró decididamente activa en la vida gremial y política de la aldea. La CGT, al igual que la UOL, organizó un sinnúmero de actos contra la carestía de la vida. También desplegó múltiples manifestaciones de adhesión al peronismo. Por otra parte, a la vez que disputó la conducción de los existentes procuró acicatear la organización de fracciones enteras de trabajadores que carecían de sindicato o se encontraban débilmente organizados. Las experiencias de este tipo no fueron escasas, aquí nombraremos las más significativas: la de los gremios de periodistas, de vendedores ambulantes (bautizado "Santa Evita"), de canillitas, de cuidadores de vehículos y de servicio doméstico. En la mayoría de los casos se hizo en el marco de una huelga para el reconocimiento patronal de la entidad sindical.

Nos detendremos un momento en la experiencia de organización de la "sirvientas". Si bien es cierto que previamente al peronismo habían existido organizaciones que agrupaban a las empleadas de casa particulares, fue bajo este gobierno que su sindicalización tomó mayor brío. En Mar del Plata, la conformación de un sindicato de "sirvientas" se produjo tardíamente, hacia comienzos de 1950 y en el marco de un caso de "abuso" patronal que, llegado a los estados del Juzgado de Paz, tomó estado público. La "sirvienta" agraviada por un "potentado" local fue la anciana María López García. En la presentación de la noticia se aclaraba que “...no es este un caso común. La actora, una mujer humilde, los actores un patrón con mucho dinero, muchos perros y poca sensibilidad para quienes se prestaron a servirle". ${ }^{43}$ Desarrollando sus tareas habituales, María fue atacada por el perro de su patrón. Ante esta situación, el "desalmado ricachón" la despidió sin contemplaciones de ningún tipo. Difundida la noticia, María recibió la solidaridad de sus vecinos/as, de gran parte de los sindicatos obreros, así como de la CGT. Fue en esa coyuntura y bajo el auspicio de esta última que se conformó el Sindicato de Trabajadores de Casas Particulares. ${ }^{44}$

Las relaciones entre la UOL y la FGL/CGT a lo largo de estos años fueron muy tensas. Esta situación se replicaba entre los sindicatos 'paralelos' de cada central. Así sucedió en el gremio del pescado y en el de la construcción, por nombrar a dos de los más numerosos y estratégicos. Sin embargo, estas tensiones no impidieron que obreros peronistas y antiperonistas confluyeran en huelgas por mejoras salariales. ${ }^{45}$ En el gremio del pescado, conducido por dirigentes peronistas, se desarrollaron conflictos con participación mancomunada de peronistas y anarquistas. Estos últimos se desempeñaban como delegados de planta, como fue el caso de Mario Neri

\footnotetext{
43 La Mañana, 28/12/1949.

${ }^{44}$ La Mañana, 13/02/1950. Sobre la experiencia sindical de las "sirvientas" durante el peronismo puede consultarse Omar Acha. "La organización sindical de las trabajadoras domésticas durante el primer peronismo”, Revista de Estudios Marítimos y Sociales 5/6, 2013 de 2012, págs. 27-39.

${ }^{45}$ Véase Agustín Nieto. "Entre anarquistas y peronistas. Organización sindical y experiencias obreras en la industria del pescado, Mar del Plata, 1942-1966", Tesis Doctoral, UNMdP, 2012.
} 


\section{Agustín Nieto}

y Rosa Rodríguez (ambos delegados de la fábrica de conservas de pescado La Soberana). Asimismo, el "antiperonismo" profesado por la UOL no impidió que esta última aunara fuerzas con el Secretaría de Trabajo y Previsión para ayudar a las familias damnificadas de San Juan (Foto 2).

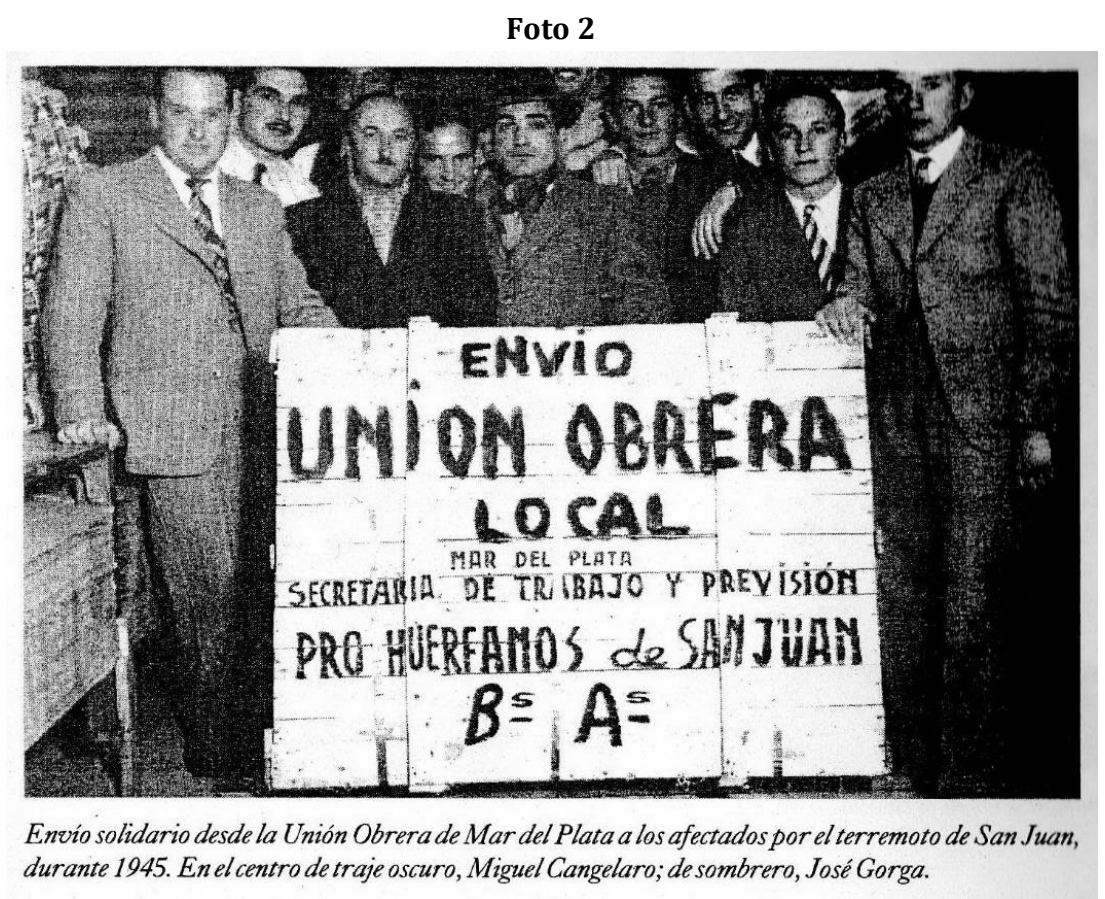

Fuente: Woollands, Recuerdos de un militante anarquista, 185.

Para finalizar este apartado, repasaremos formas de participación democrática que protagonizaron los trabajadores en base a los protocolos de la procedimentalista democracia liberal-burguesa ${ }^{46}$ Aunque no de forma constante, en determinadas coyunturas las fuerzas sociales obreras coagulan en agrupaciones que en contextos de elecciones gremiales dan origen a listas sindical en competencia. Hacia fines de marzo de 1948 se desarrollaron las elecciones en ATE. En esta ocasión la competencia electoral fue protagonizada por tres listas: la blanca, la verde, y la rosa. El 10 de octubre de 1950 el gremio gastronómico renovaba sus autoridades. Desde agosto aparecieron notas en la prensa local convocando a la presentación de listas. A medida que las listas se oficializaban aparecían los nombres de sus integrantes en la prensa. La fecha tope era el 30 de septiembre, ese último día se presentó la última de las tres listas oficializadas para competir en las elecciones del mes siguiente. El proceso electoral movilizó a 491 afiliados. La lista ganadora fue la "Azul y Blanca" con 288 votos, seguida por la "Celeste y Rosa" con 129 votos, la lista "Amarilla y Verde" obtuvo 67 votos, hubo 7 votos en blanco. ${ }^{47}$ Los primeros días del año 1951 se llevaron a cabo las elecciones en el gremio de trabajadores municipales, que había sido recientemente unificado. En dichas elecciones compitieron dos listas,

46 Al igual que en el caso de las sociedades de fomento, en muchos sindicatos las elecciones se realizaban en asambleas a mano alzada o votando al compañero/a en un papelito pero sin lista.

47 La Capital, 12/10/1950. 


\section{Vida asociativa al ras del suelo}

la A y la B, imponiéndose la primera con 480 votos sobre la segunda que obtuvo $245 .{ }^{48}$ Hacia mediados de 1954 fue el caso del gremio gráfico. El sábado 26 de junio de 1954 los obreros gráficos se reunieron en asamblea para renovar sus autoridades. El acto eleccionario se llevó a cabo en el local que la seccional marplatense de la Federación Gráfica Argentina tenía en Dorrego no 1445 entre las 9 de la mañana y las 8 de la noche. Las listas en competencia fueron dos: la lista Verde ("oficialista") ${ }^{49}$ y la lista Azul ("opositora") 50 . Fue esta última la que se hizo con el triunfo. ${ }^{51}$ Casi al unísono se desarrollaron las elecciones del gremio de taxistas. A primeras horas de la tarde del miércoles 30 de junio de 1954, previa convocatoria circulada a través de los medios de difusión locales, el Sindicato de Conductores de Taxis de Mar del Plata llevó a cabo una asamblea general cuyo orden del día incluía la presentación de listas para la renovación parcial de la Comisión Directiva. ${ }^{52} \mathrm{Al}$ igual que en el gremio gráfico, las listas presentadas fueron dos: la lista "Justicialista" (encabezada por Fernando Correa) y la lista "Blanca" (encabezada por Juan Héctor Sosa). ${ }^{53}$ Fue esta última, con 472 votos, la que se impuso en las elecciones desarrolladas el lunes 5 de julio, dándole así la reelección a la Secretario general saliente, Fernando Correa. Por su parte, la lista "Justicialista" obtuvo 120 votos. ${ }^{54}$ Con estas experiencias de elecciones sindicales "competitivas" pausamos el repaso de las variadas formas de activación y asociación obrera en la aldea marplatense, para pasar a las notas finales.

\section{Notas finales}

En las siguientes líneas intentaremos articular un racimo de reflexiones en torno a la dinámica asociativa vivida y protagonizada por activistas obrerxs y barriales en una aldea peronista del sudeste de la provincia de Buenos Aires. Consideramos que el ordenamiento de los eventos seleccionados que da sentido a nuestro relato nos permite pensar algunas líneas de interpretación alternativas sobre el asociacionismo obrero y popular para la década peronista. Este es el lugar para revisar, entre otros

\footnotetext{
48 La Mañana, 13/01/1951.

${ }^{49}$ Secretario general: Sergio José M. López Osornio; Secretario adjunto: Antonio Liborio Baldanza; Secretario de organización: Luis Bruni; Secretario de actas: Benito Arturo Lantaño; Secretario tesorero: Leonildo Rudecindo Cepeda; Vocales titulares: Fernando E. Rodríguez, Mario Cejas, Roberto Enrique Penoni y Rodolfo Gnoni; Vocales suplentes: Juan Nielsen, Martín Darío Martínez y Alberto García. El Atlántico, 24/06/1954.

50 Secretario general: Ernesto Díaz; Secretario adjunto: Basilio Palacios; Secretario de organización: Domingo De Luca; Secretario de actas: Ricardo A. Casas; Secretario tesorero: Víctor Castelli; Vocales titulares: Arturo Rodríguez, José Posat, Carlos Errezarret y Juan Ramírez; Vocales suplentes: Agustín Echaniz, Carlos López Osornio y Antonio Mosquera. El Atlántico, 25/06/1954.

51 El Atlántico, 27/06/1954.

52 El Atlántico, 22/06/1954.

53 El Atlántico, 06/07/1954.

54 El Atlántico, 01/07/1954.
} 


\section{Agustín Nieto}

aspectos, la "engañosa" división entre barrio y fábrica, dicotomía que sigue a la acostumbrada diferenciación entre identidad popular e identidad obrera. En este sentido, la presentación de estas dos dimensiones en dos apartados diferenciados responde a un seguimiento analítico de identidades diferenciadas pero amalgamadas, que no conocen de anclajes absolutos. En este ensayo no fueron tratadas como espacios sociales diferenciados ni como identidades excluyentes. Las entendemos como identidades que "habitan" mismos cuerpos. Identidades solapadas que se contaminan mutuamente generando amplias "zonas grises". Este combinado de identidades se vuelve perceptible identificando las adscripciones múltiples y cooperativas de diversos activistas políticos que se desempeñaban a un mismo tiempo como referentes barriales a la vez que sindicales. Ya vimos que así ocurría con Héctor Woollands y Agustín Navone. Pero no fueron los únicos: Eduardo Ivars, militante anarquista, se desempeñó como integrante de las comisiones directivas de la Cooperadora de la Escuela 19, de la Sociedad de Fomento Cerrito y San Salvador y activista en el SOIP (Sindicato Obrero de la Industria del Pescado); por su parte Juvenal E. Rico, militante socialista, fue parte de la Sociedad de Fomento Bario Estación Norte y de la Unión Ferroviaria; otro militante de perfil similar fue el conservador Víctor I. Mendoza, quien ocupó cargos dirigentes en la Cooperadora de la Escuela 26, en la Sociedad de Fomento Peralta Ramos Oeste y en el SOIP.

Entre los resultados provisorios que podemos recapitular en esta coda cuenta una intensa activación obrera y popular a ras del suelo en los distintos momentos del período bajo estudio, incluso en los años "duros" del "peronismo clásico" (19501955). También logramos encontrar, para aquellos años, altos grados de participación democrática en una clave no solo, ni principalmente, liberal-republicana. Nos referimos a las constantes huelgas, paros, movilizaciones, concentraciones, impulsadas y protagonizadas por las asociaciones basales de las clases subalternas. En este sentido, podemos sostener que aquellos espacios fueron "nidos de la democracia", pero de una forma no liberal. El "movimientismo" obrero y popular practicó la democracia desde las calles, las plazas, los campos y las fábricas de la aldea. Pero también la practicó participando de distintos procesos electorales, desde elegir a un delegado/a barrial o de fábrica hasta el presidente de la nación. Todo esto, como vimos, dinamizado por las fricciones entre diversas identidades político-partidarias: anarquistas, peronistas, comunistas, socialistas, etc.

En segundo lugar, vinculado a lo anterior, pudimos advertir que el asociacionismo obrero y popular se reservó una cuota de poder decisional para sí. Esto lo pudimos notar en las distintas acciones que se llevaron a cabo subordinando las identidades político-partidarias en favor de las barriales y sindicales. En este sentido es ilustrativo, pese a su alta cuota de romanticismo y optimismo, un pasaje del texto de Woollands donde sostiene que "en las sociedades de fomento las personas se agrupan movidas por la gran causa común del vecindario". ${ }^{55}$ Por su parte, en el ámbito sindical también los activistas guardaron una alta cuota de poder decisional para sí.

55 Woollands. Recuerdos de un militante anarquista, pág. 109. 


\section{Vida asociativa al ras del suelo}

Por ejemplo, en el gremio de la construcción activistas peronistas y comunista impulsaron procesos huelguísticos en procura de mejoras salariales y en sus condiciones de trabajo. Otro ejemplo ilustrativo es el ocurrido en el gremio del pescado en torno al aguinaldo. Recordemos, los integrantes la dirección del SOIP eran miembros de la FACA, organización anarquista que pregonaba contra la aceptación del aguinaldo. Sin embargo, llevada como propuesta por la dirección del SOIP a una asamblea, el aguinaldo fue aceptado por amplia mayoría. Posteriormente, cuando la nueva organización sindical de los obreros del pescado estaba dirigida por peronistas, el sindicato acompañó las demandas de los activistas de fábrica enrolados en el anarquismo ante las patronales y el fuero laboral. ${ }^{56}$ En otras palabras, estas prácticas nos permite imaginar que la adhesión de los activistas a una u otra identidad políticopartidaria nunca implicó la clausura absoluta de su poder decisional en relación a sus identidades e intereses "particularistas". En términos más abstractos, todo proceso hegemónico (por más eficaz que sea) implica un consustancial proceso contrahegemónico (por más débil que sea).

En tercer lugar, a partir de las experiencias del barrio "El Martillo" y la BPJM pudimos imaginar el carácter complementario entre las identidades barrial-popular y obrera-clasista, no solo por las adscripciones múltiples de diversos activista políticos sino por el carácter popular de las prácticas obreras y el carácter obrero de las prácticas populares. 0 sea, por el carácter fronterizo de aquel repertorio de prácticas, entre las cuales podemos listar los reclamos, la organización, la recreación, la autoconstrucción, el cooperativismo, la lectura, el deporte, entre otros. Estas mismas experiencias, condensadas en la singular figura de Héctor Woollands, también nos permitieron revisar la figura del anarquismo como prescindente del estado, la política e incapaz de adaptarse al ambiente barrial. De esta forma podemos pensar que las identidades barrial-popular y obrera-clasista, mentadas por la lente del PEHESA y reproducida por sus detractores, no se nos presentan como excluyentes ni dicotómicas. Pese a la heterogeneidad socio-ocupacional, en aquella época una gran cantidad de barrios se reconocieron y fueron reconocidos como "barrios obreros". Asimismo, lejos de la imagen dicotómica pehesiana, muchas asociaciones intermedias, como las bibliotecas, eran identificadas como populares por ser obreras y viceversa. Éstas no eran identidades en disputa sino complementarias.

En cuarto lugar, identificamos algunos indicios que habilitan una problematización inicial y nada concluyente de la inconveniente formula dicotómica "estado / sociedad civil". ${ }^{57}$ A diferencia de abordajes que los toman como polos contrapuestos y hasta antagónicos, consideramos que aquellas figuras se encuentran completamente amalgamadas en proporciones diversas, a la vez que carecen de espacios propios. Desde este ángulo, ambos entramados sociales (estado y sociedad

\footnotetext{
56 Para un tratamiento sugerente del clivaje clasista durante el peronismo consúltese Gustavo Nicolás Contreras. "Las tendencias peronistas en la Federación de la carne: prácticas gremiales y proyecciones políticas, 1946-1955”, Anuario IEHS, n. ${ }^{\circ} 28,2013$, págs. 17-35.

57 Un abordaje interesante de esta problemática la encontramos en Acha. "Sociedad civil y sociedad política durante el primer peronismo".
} 


\section{Agustín Nieto}

civil) están tensionados por articulaciones verticales de carácter cooperativo y fricciones antagónicas de vección horizontal. En este sentido los conflictos potenciales no se producen entre estado, por un lado, y sociedad civil, por el otro, (como entes monolíticos), donde el primero pretende colonizar a la segunda, sino entre partes de los entramados estatal / civil y otras partes de estos mismos entramados. Decimos esto puesto que localizamos articulaciones persistentes entre identidades políticas, asociaciones basales, organizaciones partidarias, funcionarixs gubernamentales y agencias estatales. Sucedió así tanto con peronistas como con "antiperonistas". Pensamos que fueron estas identidades políticas las que permearon y "contaminaron" al entramado estatal y civil, dos dimensiones presumidas prescindentes. La capilar infiltración de la identidad peroniana saturó rápidamente el entramado civil-estatal en caudales impensados para las identidades precedentes, provocando en aquel entramado el efecto del "corrimiento" de sus "máscaras". Un "caso testigo" que nos brinda un acercamiento a esta complejidad social es la figura de J.A. Cavallo, quien detento en aquellos años los cargos de intendente municipal, juez de los Tribunales de Trabajo, dirigente del partido peronista, presidente de la Cooperadora de la Escuela nº 5. Esta deriva del análisis abre las puertas a un debate teórico más denso, donde debemos hacer tallar, entre otros, los conceptos de estado, sociedad civil, identidades y gobierno. Podríamos conjeturar que las identidades políticas son a un tiempo "permeantes de" y "permeadas por" el entramado gubernamental y, a través de su solapamiento, el entramado cívico-estatal. 58

Recibido: 01/07/2015

Evaluado: 03/08/2015

Versión Final: 17/08/2015

\footnotetext{
58 Para el inicio de esta discusión pensamos en los siguientes textos: Philip Abrams. "Notes on the Difficulty of Studying the State", Journal of Historical Sociology, 1, n. ${ }^{\circ} 1,1988$, págs 58-89; Partha Chatterjee. La nación en tiempo heterogéneo y otros estudios subalternos, vol. 6, Instituto de Estudios Peruanos, 2006; Philip Corrigan y Derek Sayer. "La formación del Estado inglés como revolución cultural", Antropología del Estado. Dominación y prácticas contestatarias en América Latina, 2007, págs. 39-74; Antonio Gramsci. La Política y el estado moderno, Barcelona, Planeta-Agostini, 1985; Michael Taussig. Un gigante en convulsiones, Barcelona, Gedisa, 1995.
} 